\title{
A methodology to select construction equipment
}

\author{
Miquel Casals, Nuria Forcada, Xavier Roca \\ Polytechnic University of Catalonia, Department of Construction Engineering, \\ C/Colom 11, Edifici TR-5, 08221 Terrassa, Barcelona, Spain, \\ miquel.casals@upc.es
}

\begin{abstract}
Planning in the construction industry, as is well known plays an important part in the successful outcome of a project. How a task has to be dealt with and with which tools is part of the engineers work load and it is in their responsibility to assure that this planned work is carried out on time and within its constraints. Construction equipment is among these tools that have to be carefully chosen.

The traditional way to choose equipment was by its performance, in terms of maximum productivity at the lowest cost. Present pressures from governments and other institutional agencies as well as general conscience are forcing the construction industry to further adopt safety and environmental aspects in their normal way of functioning, and so every activity or process that a company carries out has to be rethought in order to achieve this integration of other parameters.

The aim of this paper is to present the results of a research project for creating a methodology to select construction equipment, combining the use of several well known methods for each of the aspects involved in the selection and using the multi-criteria analysis to reach at the final choice or recommendation.
\end{abstract}

KEYWORDS: Construction equipment, Performance, Labour risks, Minimal impact, Multi-criteria analysis.

\section{INTRODUCTION}

Planning in the construction industry, as is well known plays an important part in the successful outcome of a project. How a task is to be dealt with and with which tools, be they technical or management oriented, is part of the engineer's work load and it is his responsibility to assure that this planed work is carried out on time and within its constraints. Construction equipment is among these tools that have to be carefully chosen.

\section{METHODOLOGY}

Starting from the notion that construction equipment should be selected by its performance on site, the first stage in this research project was to choose the right method for measuring this performance. For each of the different types of equipment a specific method had to be selected. The construction equipment was divided in 6 groups:

- Earth movement equipment

- Material handling equipment

- Elevation and rising equipment

- Concrete equipment

- Auxiliary equipment

- Portable machines
And for each type the methodology used to analyze the different criteria was based in:

- Measuring the performance

- Measuring the minimal risk

- Measuring the minimal impact or environmental aspect.

- Calculating by the multi-criteria analysis method which of the options is the most suitable 
Table 1. Steps of the methodology

\begin{tabular}{||l|l||}
\hline CRITERIA & USED METHOD TO ANALYSE IT \\
\hline $\begin{array}{l}\text { Optimum } \\
\text { performance }\end{array}$ & $\begin{array}{l}\text { Minimal hourly cost } \\
\text { Maximum hourly productivity }\end{array}$ \\
\hline Minimal risk & $\begin{array}{l}\text { The minimal risk criteria, will be the result from the sum of all the present } \\
\text { risks. The valuation of these risks was made through the method proposed } \\
\text { by the INSHT. (Instituto Nacional de Seguridad e Higiene del Trabajo). }\end{array}$ \\
\hline $\begin{array}{l}\text { Minimal impact or } \\
\text { environmental aspect }\end{array}$ & $\begin{array}{l}\text { The minimal impact or environmental aspect, will be the result from the } \\
\text { sum of all the present impacts. The valuation of these impacts was made } \\
\text { through the method of identification and evaluation of environmental } \\
\text { impact and aspects based on the Environmental Management Systems } \\
\text { contained in the ISO 14001 standard. }\end{array}$ \\
\hline
\end{tabular}

\section{OPTIMUM PERFORMANCE}

\subsection{Measuring the productivity}

For each of the different types of equipment the productivity was measured by several ways, for example, in earth moving equipment, established methods were used, as the Caterpillar method for their equipment, and for other types of equipment productivity was measured on site under normal conditions of use.

\subsection{Hourly costs}

The hourly cost for each of the equipments, as in the productivity was obtained either by established methods or by doing a market research on the price for renting that equipment for a established period of time and dividing it by the actual time of usage.

\subsection{Factor the influence the performance of construction equipment}

There are several factors that can affect or influence the performance of construction equipment and that can be gathered in the following groups:

1. Routine delays:

All those factors that are derived from the inevitable equipment use, no machine can function at maximum power continuously. Maintenance falls into these kind of delays.

2. Restrictions to optimal mechanic operation:

These originate a reduction effect on production, due exclusively to limitations to its optimal operation. Slopes, angles, heights, cutting depths, etc, are all restrictions of this kind.

3. Site conditions:

Once on site different kinds of factors can affect the performance of given equipment, some are:

a) Physical conditions: topography and geology of the site, geotechnical characteristics of the ground or rocks, etc.

b) Climate: temperature, rain, snow, etc.

c) Localization of the site: how near is the site from urban centers or industrial sites for provisioning.

d) Adaptation conditions: degree of adaptation of the work team can sometimes hinder the performance of the equipment.

4. Direction and Supervision:

Organization of the workflow, planning and other management decisions can pose obstacles for maximum performance.

All of these factors were quantified in order to obtain a real production of the equipment. 
Table 2. Risk valuation

\begin{tabular}{|c|c|c|c|c|}
\hline & & \multicolumn{3}{|l|}{ Severity } \\
\hline & & LIGHT & HAZARDOUS & $\begin{array}{l}\text { EXTREMELY } \\
\text { HAZARDOUS }\end{array}$ \\
\hline & & 1 & 2 & 6 \\
\hline $\begin{array}{l}\text { Low } \\
\text { probability }\end{array}$ & 1 & $\begin{array}{l}\text { Trivial risk } \\
1\end{array}$ & $\begin{array}{l}\text { Tolerable risk } \\
2\end{array}$ & $\begin{array}{l}\text { Moderate risk } \\
6\end{array}$ \\
\hline $\begin{array}{l}\text { Medium } \\
\text { probability }\end{array}$ & 2 & $\begin{array}{l}\text { Tolerable risk } \\
2\end{array}$ & $\begin{array}{l}\text { Moderate risk } \\
4 \approx 6\end{array}$ & $\begin{array}{l}\text { Important risk } \\
12\end{array}$ \\
\hline $\begin{array}{l}\text { High } \\
\text { probability }\end{array}$ & 6 & $\begin{array}{l}\text { Moderate risk } \\
6\end{array}$ & $\begin{array}{l}\text { Important risk } \\
12\end{array}$ & $\begin{array}{l}\text { Intolerable risk } \\
36\end{array}$ \\
\hline
\end{tabular}

\section{MINIMAL RISK CRITERIA}

The minimal risk criteria is obtained as follows:

1) Identify and evaluate all the present risks of the equipment, according to the general process of risk evaluation established by the INSHT. (Instituto Nacional de Seguridad e Higiene)

2) Valuation of the found risks, by a numeric scale.

3) Finally all the values for each equipment are summed which gives the value of the minimal risk criteria

\subsection{General risk evaluation method proposed by the INSHT.}

To evaluate the present risks in the use of construction equipment the General risk evaluation method proposed by the INSHT was used and it is composed of several steps:

A. -Classification of all the work activities that require the use of construction equipment.

B. - Risk analysis

$$
\begin{aligned}
& \text { B.1. - Danger identification } \\
& \text { B.2. -Risk estimation }
\end{aligned}
$$

\section{B.2.1. - Severity}

B.2.2. -Probability

C. - Risk valuation. This valuation is made with the help of Table 2.

D. -Prepare a risk control plan

E. -Revision of the plan

\section{Minimal impact or environmental aspect}

The minimal impact or environmental impact of construction equipment is obtained as follows:

1) Identification and evaluation of all impacts present on a given equipment applying a descriptive method based on the criteria of an environmental management system as the ISO 14001 standard.

2) Valuation of the encountered impacts according to their criticality.

3) The sum of all the values of specific equipment, this result gives the "minimal impact or environmental aspect".

\subsection{Descriptive method used for identification and evaluation of environmental impacts.}

The identification is made by a questionnaire that guides the evaluation team; this tool has to be adapted to the necessities of the activity to be carried out. The questionnaire considers the following factors:

- Controlled and uncontrolled emissions

- Controlled and uncontrolled leaks

- Residue generation

- Utilisation and contamination of the ground

- Water, fuel, energy consumption

- Visual impact

- Noise and vibrations 
Table 3. Example of a proposed format

\begin{tabular}{|l|l|l|l|}
\hline \multicolumn{2}{|l|}{ Equipment: } \\
\hline \multicolumn{2}{|l|}{ Activity/Task: } \\
\hline \multicolumn{2}{|l|}{ Filled by: } & \multicolumn{2}{l|}{ Date: } \\
\hline Yes & No & Questions & Aspects (to be filled in case of an affirmative answer) \\
\hline & & $\begin{array}{l}\text { 1. Energy use? } \\
\text { 2. Use of natural resources? }\end{array}$ & Types and quantities \\
\hline & $\begin{array}{l}\text { 3. Use of chemical products? } \\
\text { materials? }\end{array}$ & Types and quantities \\
\hline & $\begin{array}{l}\text { 5. Leaks or spills? } \\
\text { 6. Atmospheric emissions? }\end{array}$ & Types and quantities \\
\hline & & Types and quantities \\
\hline
\end{tabular}

Table 4. - Impact valuation

\begin{tabular}{|c|c|c|c|c|}
\hline & & Graveness & & \\
\hline & & LOW & MEDIUM & HIGH \\
\hline & & 1 & 2 & 6 \\
\hline $\begin{array}{l}\text { Low } \\
\text { prob. }\end{array}$ & 1 & Trivial Criticalness 1 & Tolerable Criticalness 2 & Moderate Criticalness 6 \\
\hline $\begin{array}{l}\text { Mediu } \\
\text { m prob. }\end{array}$ & 2 & $\begin{array}{l}\text { Criticalness tolerable } \\
2\end{array}$ & $\begin{array}{l}\text { Moderate Criticalness } \\
4 \approx 6\end{array}$ & $\begin{array}{l}\text { Important Criticalness } \\
12\end{array}$ \\
\hline $\begin{array}{l}\text { High } \\
\text { prob. }\end{array}$ & 6 & $\begin{array}{l}\text { Moderate Criticalness } \\
6\end{array}$ & $\begin{array}{l}\text { Important Criticalness } \\
12\end{array}$ & $\begin{array}{l}\text { Intolerable Criticalness } \\
36\end{array}$ \\
\hline
\end{tabular}

Table 3 is an example of a proposed format for the questionnaire and the factors involved in the analysis of the environmental impacts.

In this identification a problem arises, that is, up to what point or how exhaustive does the person analyzing the environmental impacts has to be, given that every equipment has to some degree implicit impacts. For this research project, logic was predominant over the extensive search for impacts, so a reasonable amount of impacts were identified and evaluated. In any case as the method is used over a period of time, preventive measures adopted can give way to more strict and extensive list of environmental impacts.

\subsection{Multi-criteria analysis}

This technique evaluates the different alternatives through punctuation according to the criteria involved in the analysis of the objectives set, and gives specific weight to each of the criteria according to its relative importance. The format of the method was adopted from Dell'Isola (1997), based on a combination between two matrixes, one of the punctuation of the criteria and the other the analysis of the alternatives. The basic steps are as follows:

a Step 1: Selection of the criteria, which are placed on the left side of the punctuation matrix followed by a letter and ordered in 
alphabetical order. The criteria have to have some degree of independence between them.

- Step 2: Assignment of punctuation to each of the criteria according to its relative importance. This punctuation has to be as objective as possible so fro this research project the following table was used to assign the relative weight.

Table 5. - Taxation scale of the degree of preference between criteria, Dell'Isola (1997).

4 Higher degree of preference over the other criteria

3 Medium degree of preference over the other criteria

2 Lesser degree of preference over the other criteria

1 No degree of preference between criteria

As an example two valuations have been made in Figure 1 , the $\mathrm{C} / 2$, stands for a lesser degree of preference of the $\mathrm{C}$ criteria when compared with the A criteria. The $\mathrm{B} / 1$ punctuation means that between criteria $\mathrm{B}$ and $\mathrm{D}$ there is no degree of preference.

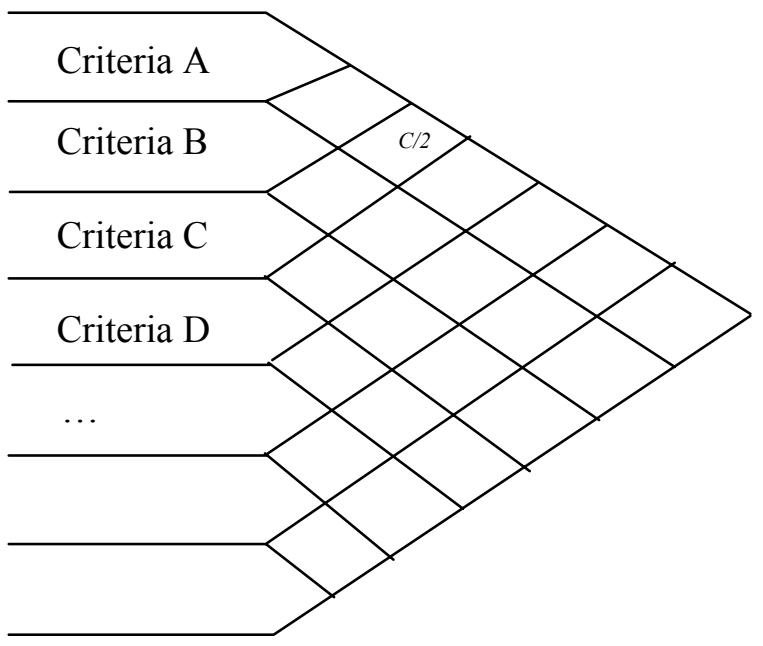

Figure 1. Punctuation matrix

- Step 3: Once the comparisons have been completed, the raw score has to be established for each of the criteria. This score is the result of the sum of the taxation of the previous step. This enables the establishment of the relative weight for each of the criteria in a scale form 1 to 10. The highest raw score gets 10 points, and to the 0 value gets the minimal weight, 1 . The rest of the values are assigned in a linear manner according to the established values. Figure 2 is an example of this raw score assignment.

- Step 4: Having obtained the relative weights for each of the criteria in a scale form 1 to 10 , the analysis of each of the alternatives is the next step. To have a common scale for all of the criteria established the values obtained in each of the criteria have to be normalized by a linear equation:

Linear equation:

$$
Y=\frac{y_{1}-y_{0}}{x_{1}-x_{0}}\left(x-x_{0}\right)+y_{0}
$$

- Step 5: Finally each valuation is reflected in the matrix by multiplying the relative weight of each criterion by its specific value.

- Step 6: To end the analysis the final step is to obtain the global score for each alternative by adding the results of each individual criterion and placing this result on the right column of the matrix. The optimal solution or alternative is the one with the lowest score, when there are similar scores various alternatives can be selected. Figure 3 is an example of the final matrix. 


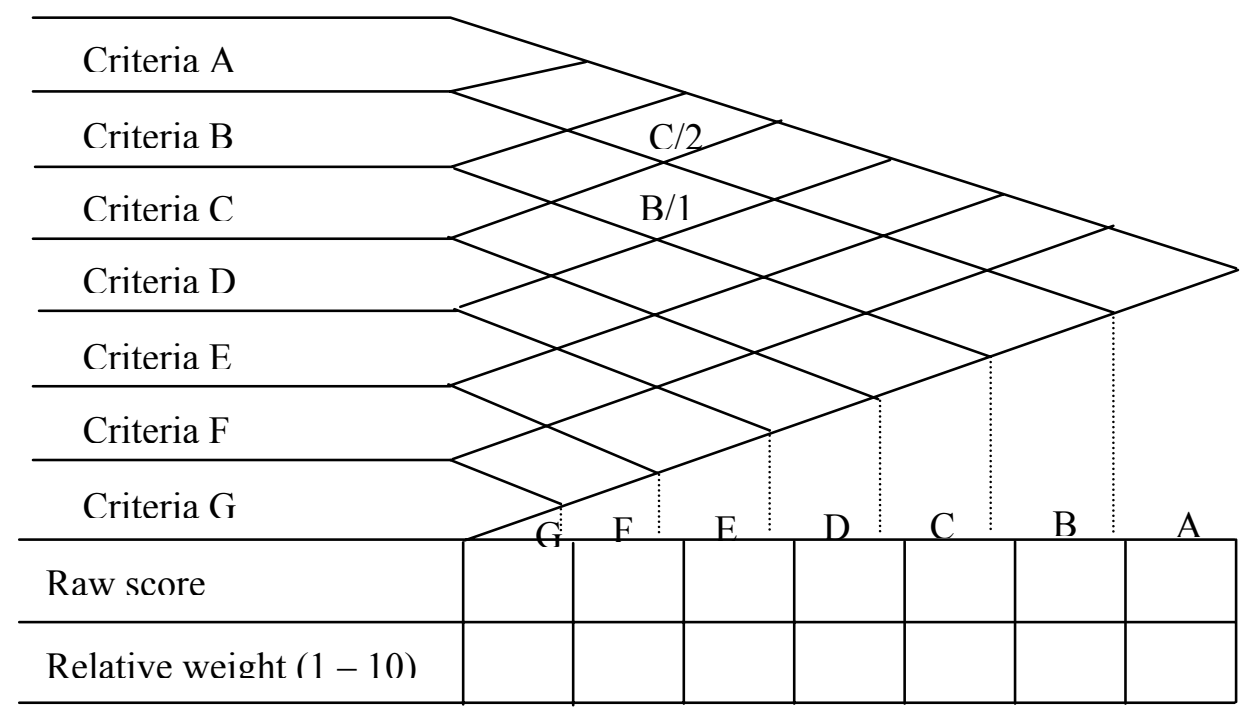

Figure 2. - Punctuation matrix with raw score and relative weight for each of the criteria

\begin{tabular}{|c|c|c|c|c|c|c|c|c|}
\hline \multirow{2}{*}{$\begin{array}{l}\text { Valuation of each } \\
\text { alternative according to } \\
\text { step } 4\end{array}$} & & & \multicolumn{6}{|c|}{$\begin{array}{l}\text { Valuation of each alternative according } \\
\text { to step } 5\end{array}$} \\
\hline & $\mathrm{G}$ & $\mathrm{F}$ & $E$ & D & $\mathrm{C}$ & $\mathrm{B}$ & A & TOTAL \\
\hline \multicolumn{9}{|l|}{ Alternative 1} \\
\hline \multirow{2}{*}{\multicolumn{9}{|c|}{ Alternative 2}} \\
\hline \multirow{2}{*}{\multicolumn{9}{|c|}{ Alternative 3}} \\
\hline & & & & & & & & \\
\hline \multicolumn{9}{|l|}{ Alternative 4} \\
\hline \multicolumn{9}{|l|}{ Alternative 5} \\
\hline \multicolumn{9}{|l|}{ Alternative 6} \\
\hline & & & & & & & & \\
\hline$\cdots$ & & & & & & & & \\
\hline
\end{tabular}

Figure 3. - Alternative analysis matrix as established by Dell'Isola (1997)

\section{CONCLUSIONS}

The described method for the selection of construction equipment has proven its results in practical cases and has been of great help to the persons responsible for this kind of decisions. Although some time and effort has to be invested in the development of all the criteria for each of the equipment involved in a construction project the decisions can be supported on a scientific method, thus being able to take less risks when purchasing equipment.

\section{REFERENCES}

[Dell'Isola, 1997] Dell'Isola, Alphonse J. 1997, Value engineering : practical applications for design, construction, maintenance \& operations. Kingston : R. S. means company, c1997 